\title{
Numerical and Experimental Investigation of Intra-Particle Heat Transfer and Tar Decomposition during Pyrolysis of Wood Biomass*
}

\author{
Pious O. OKEKUNLE**, Teeranai PATTANOTAI**, Hirotatsu WATANABE** \\ and Ken OKAZAKI** \\ **Department of Mechanical and Control Engineering, Graduate School of Engineering, \\ Tokyo Institute of Technology \\ 2-12-1-16-7, Ookayama, Meguro-ku, Tokyo, Japan \\ E-mail: watanabe.h.ak@m.titech.ac.jp
}

\begin{abstract}
Pyrolysis of cylindrical woody biomass has been investigated both numerically and experimentally with emphasis on intra-particle heat transfer and tar decompostion. In experiment, wood cylinder of $8 \mathrm{~mm}$ diameter and $9 \mathrm{~mm}$ length was pyrolyzed in an infrared reactor exposed to both convective and radiative heat fluxes in argon environment. The final reactor temperature was $973 \mathrm{~K}$, and heating rate was 5, 10 and $30 \mathrm{~K} / \mathrm{s}$. Three K-type thermocouples were located in the sample to measure intra-particle temperature history. The weight fraction history and intra-particle temperature profiles were measured at different runs. Tar was obtained at a cold trap. In calculation, a two-dimensional, unsteady state single particle model was developed and used to simulate the pyrolysis process. Wood cylinder was modeled as an isotropic porous solid. Solid mass conservation equations were solved by using first-order Euler Implicit Method. Gas phase mass conservation equations and energy conservation equation were discretised by finite volume method. In order to investigate the effect of intra-particle heat transfer, simulations were carried out, first, by considering temperature gradient and second, by assuming uniform temperature within the sample. When temperature gradient was considered, simulation results were in good agreement with experimental data. When uniform intra-particle temperature was used in the simulation, simulation results were quite different from experimental measurements, the degree of difference increasing with increase in heating rate. Both calculation and experiment showed tar yield decreased with increasing heating rate. This was because tar formation reaction and intra-particle tar decomposition reactions were enhanced by increase in heating rate but the latter was dominant. It was shown that intra-particle heat transfer and tar decomposition played an important role in pyrolysis characteristics of wood cylinder.
\end{abstract}

Key words: Biomass, Pyrolysis, Intra-Particle Heat Transfer and Intra-Particle Tar Decompostion

\section{Introduction}

An increase in the world population and the rise in standards of living all over the world have resulted in a high increase in energy demand. Increasing $\mathrm{CO}_{2}$ emissions and the depletion of conventional fossil fuel resources have compounded the energy challenges. As a result, new energy sources, which are renewable and environmentally friendly, have

[DOI: 10.1299/jst.6.360]

Copyright (C) 2011 by JSME 
attracted interest. Biomass energy technology amongst others is a promising option ${ }^{(1,2)}$. Although, there are various biomass conversion methods, thermo-chemical conversion is often employed. Gasification and pyrolysis are the most common processes in thermo-chemical conversion ${ }^{(3)}$. Unlike coal particles, biomass particles used in combustors and gasifiers are much larger because biomass materials cannot be economically processed into very fine sizes due to a higher volatile content and moisture level. According to the Swedish standard, the diameter of pellet is $6-8 \mathrm{~mm}{ }^{(4)}$. Moreover, the average thermal conductivity of biomass is very low. Therefore, it is important to discuss the effect of intra-partcle heat transfer on pyrolysis. Although researchers have investigated the effect of heat transfer during biomass pyrolysis ${ }^{(5-7)}$, numerical and experimental information available about the effect of heating rate on intra-particle transport phenomena is insufficient.

In pyrolysis and gasification, aside from gaseous fuel yield, tar and char are also formed. Tar in product gases is a contaminant. At low temperature, tar condenses, fouling process equipment and limiting the end-use of biosyngas in engines and turbines. Therefore, one of the main problems in biomass pyrolysis and gasification is tar contamination. Some researchers have reported primary and secondary methods for tar reduction ${ }^{(8,9)}$. Primary methods are all measures taken during gasification process to prevent tar formation or to convert the tar formed in the gasifier. Secondary methods are used as treatments to the hot product gas downstream the gasifier. As a primary measure for tar reduction, proper selection of the operating conditions is of prime importance. Many researchers have studied biomass pyrolysis numerically and experimentally ${ }^{(10-14)}$ but insignificant attention has been given to investigating the possibility of tar reduction through intra-particle tar decomposition. In order to study intra-particle transport phenomena and tar decomposition, numerical simulation is a useful tool. At present, many simplified reaction mechanisms exist for the study of biomass pyrolysis. These are either one-step global models ${ }^{(15-19)}$ or one- or two-stage multiple reaction models ${ }^{(20,21-26)}$. Di Blasi (27) and Prakash and Karunanithi ${ }^{(28)}$ have given some comprehensive reviews of advances in modeling and simulation of chemical and physical processes of wood and biomass pyrolysis. Park et al. investigated that thermal decomposition of $25.4 \mathrm{~mm}$ diamter dry wood spheres both experimentally and numerically ${ }^{(29)}$. In their work, wood spheres were pyrolyzed at temperature ranging from $638 \mathrm{~K}$ to $879 \mathrm{~K}$, and they revealed internal pressure build up was different at different heating rate. However, intra-particle tar decomposition was not discussed well.

The purpose of this study is to investigate intra-particle heat transfer and tar decomposition experimentally and numerically. The possibility of tar reduction through intra-particle tar decomposition is discussed at different heating rates during biomass pyrolysis.

\section{Experiment}

Figure 1 shows a schematic diagram of the experimental set-up. The experimental set-up essentially consists of a thermo-balance (ALVAC, TGD-9600), a reaction tube and tar trap. Sample weight loss was measured by the thermo-balance. A Japanese cypress wood cylinder $(\phi 8 \mathrm{~mm} \times 9 \mathrm{~mm})$, cut from trunk, was put in a Pt cell $(0.5 \mathrm{~mm}$ thickness $)$ with the thermometric point. Table 1 and 2 show ultimate analysis and proximate analysis of wood cylinder used in this research, respectively. Argon at ambient temperature was used to purge the reactor. At the outset of each run, wood cylinder $\left(\rho=400 \mathrm{~kg} / \mathrm{m}^{3}\right)$ was dried at a temperature of $383 \mathrm{~K}$ for at least $10 \mathrm{~min}$. Pyrolysis process was performed at three different heating rates $(5,10$ and $30 \mathrm{~K} / \mathrm{s})$ in the atmosphere of argon flowing at $0.8 \mathrm{l} / \mathrm{min}$. Heating rate was controlled by the thermometric point. The thermometric point temperature 
increased linearly up to $973 \mathrm{~K}$ and was kept constant at this temperature until the sample weight remained constant. Wall temperature of tube from thermobalance to tar trap was set to $473 \mathrm{~K}$ to prevent tar from attachment. Tar was collected at the ice-cold trap. Tar is defined as condensable compounds collected at the cold trap in this experiment.

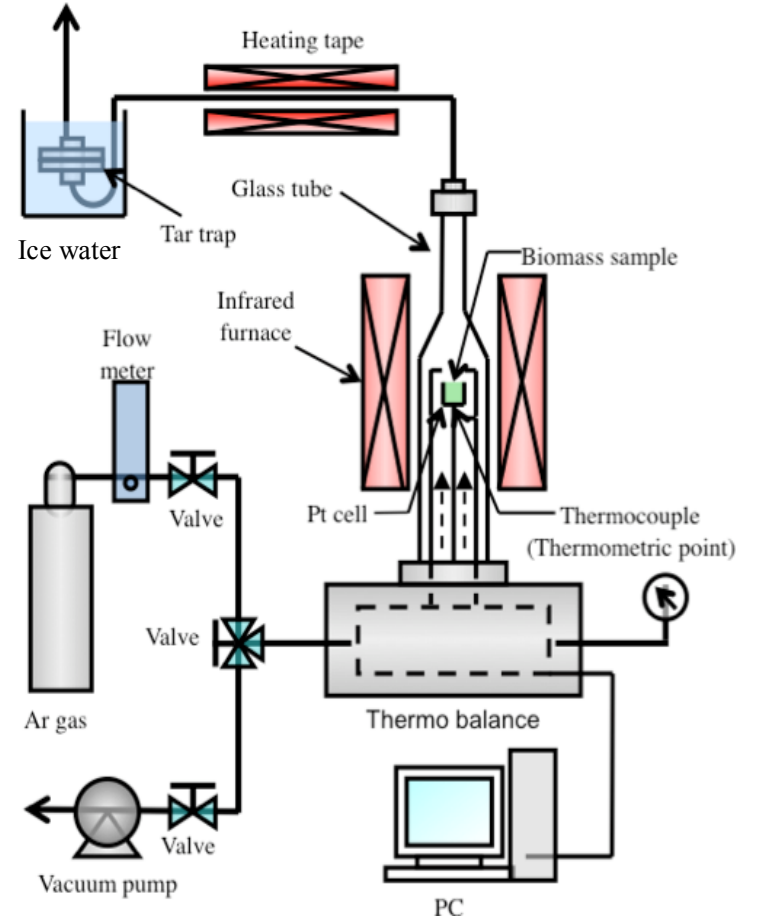

Table 1 Ultimate analysis

\begin{tabular}{cc}
\hline Element & wt \% d. a. f. \\
\hline $\mathrm{C}$ & 51.5 \\
$\mathrm{H}$ & 6.2 \\
$\mathrm{O}$ & 42.2 \\
$\mathrm{~N}$ & 0.1 \\
$\mathrm{~S}$ & 0.0 \\
\hline
\end{tabular}

Table 2 Proximate analysis

\begin{tabular}{cc}
\hline Content & wt $\%$ \\
\hline Volatile matter & 78.7 \\
Fixed carbon & 13.2 \\
Ash & 0.2 \\
Moisture & 7.9 \\
\hline
\end{tabular}

Figure 1 Schematic diagram of the experimental set-up

Figure 2 shows photograph of wood cylinder and thermocouple position. Wood cylinder was put on the Pt cell with inner diameter of $10 \mathrm{~mm}$. The temperature distribution was measured by three K-type thermocouple probes $(0.5 \mathrm{~mm}$ diameter $)$ inserted through $0.5 \mathrm{~mm}$ diameter drilled holes in the sample. The radial positions of three thermocouples are $0,1,2$ $\mathrm{mm}$, respectively. A data logger (MEMORY HILOGGER 8430, Hioki Corp.) acquired temperature data from the thermocouple with an interval of $500 \mathrm{~ms}$. The mass loss and temperature histories were measured at different runs. Heat flow through the thermocouples to the sample was quite lower than that from infrared furnace to the sample and has insignificant effect on the result.
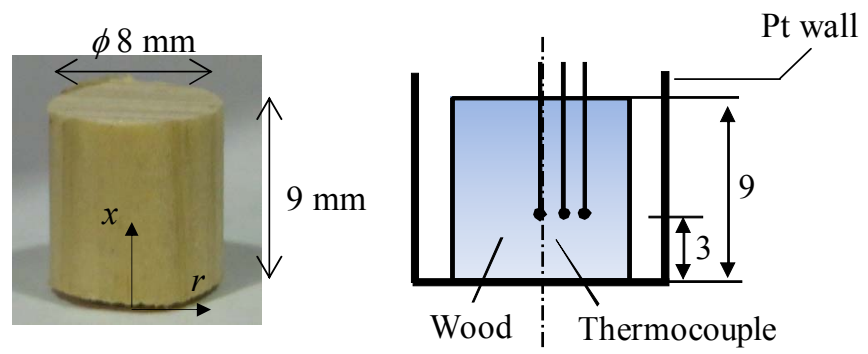

Figure 2 Photograph of wood cylinder and thermocouple position

\section{Mathematical model}

Figure 3 shows the structure of the model used in this study. This model is a combination of the models proposed by Park et al. ${ }^{(29)}$ and Suuberg et al. ${ }^{(20)}$. The model proposed by Park et al. ${ }^{(29)}$ well reproduces pyrolysis process, however, secondary tar, which is important to discuss intra-particle tar decomposition, does not included. Moreover, at high heating rate, 
tar evaporation is the limiting process, as the situation treated by Suuberg et al. ${ }^{(20)}$. In Suuberg's model, tar is divided into primary and secondary tars. Primary tar is liquid while secondary tar is in gaseous phase. Primary tar is converted to gas, secondary tar and char: this scheme ${ }^{(20)}$ was used in this work. The secondary tar, however, was not separated from gas in their model. In order to separate volatile yields resulting from secondary tar decomposition, therefore, stoichiometric coefficients $a$ and $b$ are used ${ }^{(30)}$. Coefficients $a$ and $b$ express the fraction of primary tar converted to gas and secondary tar respectively and the values were used as shown in ${ }^{(30)}$. Secondary tar included water in this research.

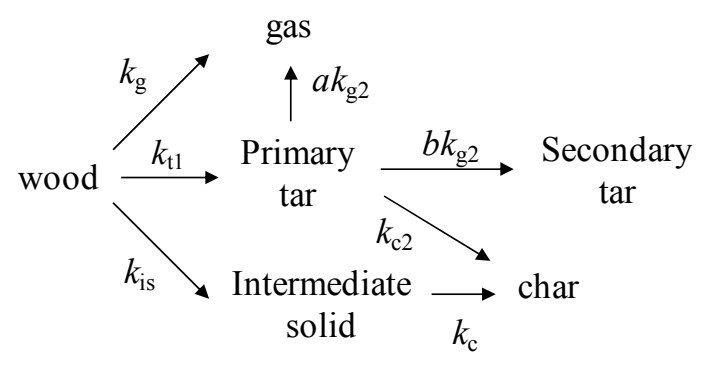

Figure 3 Pyrolysis model used in this research

As shown in the Figure 3, wood first decomposes by three endothermic competing primary reactions into gas, primary tar and intermediate solid ${ }^{(29)}$. The primary tar further undergoes secondary reactions ${ }^{(20)}$. Tar is an extremely complex mixture of organic compounds, a huge number of chemical reactions would be required to describe the details of its transformation during secondary reactions. These reactions may include cracking, partial oxidation, re-polymerization, condensation ${ }^{(31)}$ and evaporation ${ }^{(20)}$. Therefore, some simplified assumptions have to be made because it is generally difficult to account for all these reactions. Wood consists of three major components: hemicelluloses (25-35\%), cellulose $(40-50 \%)$ and lignin $(16-33 \%){ }^{(29)}$, the most major component is cellulose. Levoglucosan is known to be a major component of cellulose tar ${ }^{(20)}$. Therefore, for simplification, primary tar is assumed to be levoglucosan.

Table 3 shows the kinetic parameters used for the pyrolysis model. Reaction kinetics parameters proposed by Park et al. and Suuberg et al. are used in this research. As in other related pyrolysis modeling studies, all secondary reactions undergone by the primary tar are assumed to be exothermic ${ }^{(29,32)}$. This assumption has been experimentally supported ${ }^{(33)}$. Reaction rates were assumed to follow Arrhenius expression of the form $k_{i}=A_{i} \exp \left(-E_{i} / R T\right)$. Arrhenius parameters and reaction enthalpies are as used in Park et al. ${ }^{(30)}$ except the Arrhenius parameters for secondary tar decomposition reactions to yield gas and secondary tar, which were taken from Suuberg et al. ${ }^{(20)}$. The heats of reactions were assumed to be constant over the considered temperature range.

Table 3 Kinetic parameters and heat of reaction

\begin{tabular}{llll}
\hline Reaction $i$ & $A_{i} \quad(1 / \mathrm{s})$ & $E_{i}(\mathrm{~J} / \mathrm{mol})$ & $\Delta h_{i}[\mathrm{~kJ} / \mathrm{kg}]$ \\
$\mathrm{g}$ & $4.38 \times 10^{9(26)}$ & $152,700^{(26)}$ & $80^{(26)}$ \\
$\mathrm{t} 1$ & $1.08 \times 10^{10(26)}$ & $148,000^{(26)}$ & $80^{(26)}$ \\
$\mathrm{is}$ & $3.75 \times 10^{6(26)}$ & $111,700^{(26)}$ & $80^{(26)}$ \\
$\mathrm{c}$ & $1.38 \times 10^{10(26)}$ & $161,000^{(26)}$ & $-300^{(26)}$ \\
$\mathrm{c} 2$ & $1.0 \times 10^{5(26)}$ & $108,000^{(26)}$ & $-42^{(26)}$ \\
$\mathrm{g} 2$ & $3.30 \times 10^{11(16)}$ & $141,000^{(16)}$ & $-42^{(26)}$ \\
\hline \multicolumn{4}{c}{}
\end{tabular}




\section{Numerical simulation}

\subsection{Governing equations}

The governing equations include the mass conservation equations and energy equation. Model assumptions in this study include the following:

- Sample can be described by a two-dimensional, time dependent computational domain.

- Local thermal equilibrium exists between solid and gas phases within the particle. This implies that the gas leaving the particle readily heats up to the temperature of the wood char through which it flows ${ }^{(13)}$.

- Components in gas phase obey ideal gas law.

- Sample volume does not change during pyrolysis.

- Diffusive transport of gaseous species within the particle pores is negligible. This implies that only mass flux by convection is considered since the effect of diffusion is very small compared to convection ${ }^{(13)}$. The effect of natural convection on pyrolysis is also negligible. - Gasification reaction caused by $\mathrm{H}_{2} \mathrm{O}$ and $\mathrm{CO}_{2}$ released during pyrolysis is not considered. Jarvinen et al. have investigated this gasification, and pointed out this gasification became important when temperature exceeded $1073 \mathrm{~K}$ while devolatilization were still occurring in large particle ${ }^{(34)}$. In general, char gasification by $\mathrm{H}_{2} \mathrm{O}$ and $\mathrm{CO}_{2}$ is progressed over around $1073 \mathrm{~K}$. In our experiment, however, maximum temperature is less than $1000 \mathrm{~K}$. Therefore, the gasification is negligible.

\subsection{Solid mass conservation equation}

The virgin biomass solid instantaneous mass balance contains three consumption terms, each for the reaction yielding gas, primary tar and intermediate solid:

$$
\frac{\partial \rho_{\mathrm{s}}}{\partial t}=-\left(k_{\mathrm{t} 1}+k_{\mathrm{g}}+k_{\mathrm{is}}\right) \rho_{\mathrm{s}}
$$

The intermediate solid instantaneous mass balance contains two terms, one from the conversion of biomass to intermediate solid and the other for the conversion of the intermediate solid to char as given by Eq. (2).

$$
\frac{\partial \rho_{\text {is }}}{\partial t}=k_{\text {is }} \rho_{\mathrm{s}}-k_{\mathrm{c}} \rho_{\text {is }}
$$

Similarly, the char instantaneous mass balance contains two terms, one for the conversion of the intermediate solid to char and the other from the secondary reactions of primary tar to yield char as given below:

$$
\frac{\partial \rho_{\mathrm{c}}}{\partial t}=k_{\mathrm{c}} \rho_{\mathrm{is}}+\varepsilon k_{\mathrm{c} 2} \rho_{\mathrm{t} 1}
$$

\subsection{Mass conservation equations of gas phase components}

Mass conservation equations for all gas phase components are expressed by two-dimensional cylindrical coordinate system consisting of both temporal and spatial gradients and source term.

$$
\begin{gathered}
\operatorname{Ar}: \frac{\partial\left(\varepsilon \rho_{\mathrm{Ar}}\right)}{\partial t}+\frac{\partial\left(\rho_{\mathrm{Ar}} U\right)}{\partial z}+\frac{1}{r} \frac{\partial\left(r \rho_{\mathrm{Ar}} V\right)}{\partial r}=0, \\
\text { Gas: } \frac{\partial\left(\varepsilon \rho_{\mathrm{g}}\right)}{\partial t}+\frac{\partial\left(\rho_{\mathrm{g}} U\right)}{\partial z}+\frac{1}{r} \frac{\partial\left(r \rho_{\mathrm{g}} V\right)}{\partial r}=S_{\mathrm{g}},
\end{gathered}
$$

Primary tar:

$$
\frac{\partial\left(\varepsilon \rho_{\mathrm{t} 1}\right)}{\partial t}+\frac{\partial\left(\rho_{\mathrm{t} 1} U\right)}{\partial z}+\frac{1}{r} \frac{\partial\left(r \rho_{\mathrm{t} 1} V\right)}{\partial r}=S_{\mathrm{t} 1},
$$


Secondary tar:

$$
\frac{\partial\left(\varepsilon \rho_{\mathrm{t} 2}\right)}{\partial t}+\frac{\partial\left(\rho_{\mathrm{t} 2} U\right)}{\partial z}+\frac{1}{r} \frac{\partial\left(r \rho_{\mathrm{t} 2} V\right)}{\partial r}=S_{\mathrm{t} 2} .
$$

$S_{\mathrm{g}}, S_{\mathrm{t} 1}$ and $S_{\mathrm{t} 2}$ are the source terms for gas, primary tar and secondary tar respectively and are given by:

$$
\begin{aligned}
& S_{\mathrm{g}}=k_{\mathrm{g}} \rho_{\mathrm{s}}+\varepsilon k_{\mathrm{g} 2} \rho_{\mathrm{t} 1} \\
& S_{\mathrm{t} 1}=k_{\mathrm{t} 1} \rho_{\mathrm{s}}-\varepsilon\left[k_{\mathrm{c} 2}+(a+b) k_{\mathrm{g} 2}\right] \rho_{\mathrm{t} 1} \\
& S_{\mathrm{t} 2}=\varepsilon b k_{\mathrm{g} 2} \rho_{\mathrm{t} 1}
\end{aligned}
$$

Intra-particle tar and gas transport velocity is estimated by using Darcy's law,

$$
\begin{aligned}
& U=-\frac{B}{\mu}\left(\frac{\partial P}{\partial z}\right) \\
& V=-\frac{B}{\mu}\left(\frac{\partial P}{\partial r}\right)
\end{aligned}
$$

where $\mu$ is the viscosity. Porosity, $\varepsilon$, is expressed as:

$$
\varepsilon=1-\frac{\rho_{\mathrm{s}, \mathrm{sum}}}{\rho_{\mathrm{w}, 0}}\left(1-\varepsilon_{\mathrm{w}, 0}\right)
$$

where $\varepsilon_{\mathrm{w}, 0}, \rho_{\mathrm{s} \text {,sum }}$ and $\rho_{\mathrm{w}, 0}$ are the initial porosity of wood, the sum of solid mass density and initial wood density, respectively. The permeability $B$ of the charring woody biomass is expressed as a linear mass interpolation between the solid phase components, given as:

$$
B=(1-\eta) B_{\mathrm{w}}+\eta B_{\mathrm{c}}
$$

where $\eta$ is the degree of pyrolysis and is defined as:

$$
\eta=1-\frac{\rho_{\mathrm{s}}+\rho_{\mathrm{is}}}{\rho_{\mathrm{w}, 0}}
$$

\subsection{Energy conservation equation}

The energy conservation equation is given as:

$$
\begin{aligned}
& \left(C_{\mathrm{p}, \mathrm{w}} \rho_{\mathrm{s}}+C_{\mathrm{p}, \mathrm{w}} \rho_{\mathrm{is}}+C_{\mathrm{p}, \mathrm{c}} \rho_{\mathrm{c}}+\varepsilon C_{\mathrm{p}, \mathrm{t}} \rho_{\mathrm{t} 1}+\varepsilon C_{\mathrm{p}, \mathrm{t}} \rho_{\mathrm{t} 2}+\varepsilon C_{\mathrm{p}, \mathrm{g}} \rho_{\mathrm{g}}\right) \frac{\partial T}{\partial t} \\
& =\frac{\partial}{\partial z}\left(\lambda_{\text {eff }(z)} \frac{\partial T}{\partial z}\right)+\frac{1}{r} \frac{\partial}{\partial r}\left(r \lambda_{e f f(r)} \frac{\partial T}{\partial r}\right)+Q
\end{aligned}
$$

where $Q$ is the heat generation, given by:

$$
\begin{aligned}
Q= & -\left(k_{\mathrm{t} 1} \Delta h_{\mathrm{t} 1}+k_{\mathrm{g}} \Delta h_{\mathrm{g}}+k_{\mathrm{is}} \Delta h_{\mathrm{is}}\right) \rho_{\mathrm{s}}-k_{\mathrm{c}} \Delta h_{\mathrm{c}} \rho_{\mathrm{is}} \\
& -\varepsilon\left(k_{\mathrm{c} 2} \Delta h_{\mathrm{c} 2}+(a+b) k_{\mathrm{g} 2} \Delta h_{\mathrm{g} 2}\right) \rho_{\mathrm{t} 1}
\end{aligned}
$$

The primary pyrolysis reactions have the same heat of reaction as shown in Table 3.

Effective thermal conductivity of the particle comprises of both the conductive and radiative components, given by:

$$
\lambda_{\text {eff }(i)}=\lambda_{\operatorname{cond}(i)}+\lambda_{\mathrm{rad}} \quad(i=z, r)
$$


where $\lambda_{\text {cond }}$ and $\lambda_{\text {rad }}$ are calculated as the weighted sum of virgin wood, char and volatiles conductivity and accounting for radiation heat transfer through the pore.

$$
\begin{aligned}
& \lambda_{\text {cond }(i)}=(1-\eta) \lambda_{\mathrm{w},(i)}+\eta \lambda_{\mathrm{c}(i)}+\varepsilon \lambda_{\mathrm{v}} ;(i=z, r) \\
& \lambda_{\mathrm{rad}}=\frac{13.5 \sigma T^{3} d_{\text {pore }}}{e}
\end{aligned}
$$

where $\sigma, e$ and $d_{\text {pore }}$ are the Stefan-Boltzmann constant, emissivity and pore diameter respectively. Table 4 shows the properties of the biomass sample.

\subsection{Pressure evolution}

Total pressure is the sum of the partial pressures of argon (inert gas), gas and secondary tar.

$$
P=P_{\mathrm{Ar}}+P_{\mathrm{t} 2}+P_{\mathrm{g}} ; P=\frac{\rho R T}{M}
$$

where $M$ and $R$ are the molecular weight and the universal gas constant respectively. Combining equations (4), (5) and (7), (11) - (12) and (21), the total pressure equation is given by:

$$
\frac{\partial}{\partial t}\left(\varepsilon \frac{P}{T}\right)-\frac{\partial}{\partial z}\left[\frac{B P}{\mu T}\left(\frac{\partial P}{\partial z}\right)\right]-\frac{1}{r} \frac{\partial}{\partial r}\left(r \frac{B P}{\mu T} \frac{\partial P}{\partial r}\right)=\frac{R}{M_{\mathrm{t} 2}} S_{\mathrm{t} 2}+\frac{R}{M_{\mathrm{g}}} S_{\mathrm{g}}
$$

\section{Numerical procedure}

Wood cylinder was modeled as an isotropic porous solid. The pores were assumed to be filled initially with argon. As the solid was pyrolyzed, tar and gas were formed while argon was released to the outer region. The solid mass conservation equations (eqs. (1) - (3)) were solved by first-order Euler Implicit Method. The mass conservation equations for gas and tars (eqs. (4) - (7)), energy conservation equation (eq. (16)) and the total pressure equation (eq. (22)) were discretised using finite volume method. Hybrid differencing scheme was adopted for the convective terms. First-order fully implicit scheme was used for the time integral with time step of $0.005 \mathrm{~s}$.

The computational grid numbers of the axial and radial directions were 80 and 40 respectively. The resulting simultaneous equations were solved by Tri-Diagonal Matrix Algorithm (TDMA). Simulation converged when any of the normalized residuals of gas phase equations was less than or equal to 0.001 . The residual was a measure of the overall conservation of the flow parameters. The grid numbers and time steps were determined after a number of runs to find out the effect of grid numbers and time steps on calculation results. Therefore, the grid numbers and time step chosen were adequate for this calculation.

Figure 4 shows a schematic diagram of the computational domain and boundary conditions. Top and side boundaries were exposed to the surrounding gas, and bottom boundary contacted with Pt cell. Therefore, the convective and radiative heat fluxes were given as the top and side boundary conditions, and bottom temperature was given as the bottom boundary condition. $T_{\text {gas }}$ and $T_{\text {wall }}$ were given by measurement. Previous work estimated convective heat transfer coefficient $\left(h_{\mathrm{c}}\right)$ around wood cylinder during pyrolysis ${ }^{(35)}$. Since their experimental conditions including fluid charactertistics are similar to those in this work, the same convective heat transfer coefficient was used in the calculation. Flow rate of Argon was much larger than amount of released tar in this work. Therefore, for simplification, released tar and gas were removed from solid surface immediately. In fact, it was assumed that the solid surface were exposed to Argon $\left(\rho_{\mathrm{Ar}, \text { bulk }}\right)$ directly, and other gases mass concentration at the bulk ( $\left.\rho_{\mathrm{g}, \text { bulk }}, \rho_{\mathrm{t} 1 \text {,bulk }}, \rho_{\mathrm{t} 2 \text {,bulk }}\right)$ were set to 0 , respectively. 
Table 4 Physical properties of wood sample

\begin{tabular}{|c|c|c|}
\hline Property & Value & Ref. \\
\hline$C_{\mathrm{p}, \mathrm{w}}$ & $1500+1.0 \times T[\mathrm{~J} / \mathrm{kgK}]$ & $(30)$ \\
\hline$C_{\mathrm{p}, \mathrm{c}}$ & $420+2.0 T+6.85 \times 10^{-4} T^{2}[\mathrm{~J} / \mathrm{kgK}]$ & $(30)$ \\
\hline$C_{\mathrm{p}, \mathrm{t}}$ & $-100+4.4 T+1.57 \times 10^{-3} T^{2}[\mathrm{~J} / \mathrm{kgK}]$ & $(30)$ \\
\hline$C_{\mathrm{p}, \mathrm{g}}$ & $770+0.629 T-1.91 \times 10^{-4} T^{2}[\mathrm{~J} / \mathrm{kgK}]$ & $(30)$ \\
\hline$d_{\text {pore }}$ & $5 \times 10^{-5}(1-\eta)+1 \times 10^{-4} \eta[\mathrm{m}]$ & $(30)$ \\
\hline$\sigma$ & $5.67 \times 10^{-8}\left[\mathrm{~W} / \mathrm{m}^{2} \mathrm{~K}^{4}\right]$ & $(30)$ \\
\hline$B_{\mathrm{w}}$ & $5 \times 10^{-16}\left[\mathrm{~m}^{2}\right]$ & $(30)$ \\
\hline$B_{\mathrm{c}}$ & $1 \times 10^{-13}\left[\mathrm{~m}^{2}\right]$ & $(30)$ \\
\hline$e$ & $0.95[-]$ & $(5)$ \\
\hline$h_{\mathrm{c}}$ & $8.4\left[\mathrm{Wm}^{-2} \mathrm{~K}^{-1}\right]$ & $(35)$ \\
\hline$\mu$ & $3.0 \times 10^{-5}[\mathrm{~kg} / \mathrm{ms}]$ & $(30)$ \\
\hline$P_{0}$ & atomospheric pressure (measured) & \\
\hline $\mathrm{R}$ & $8.314[\mathrm{~J} / \mathrm{molK}]$ & \\
\hline$\lambda_{\mathrm{w}, \text { radial }}$ & $0.071[\mathrm{~W} / \mathrm{mK}]$ & $(30)$ \\
\hline$\lambda_{\mathrm{w}, \text { axial }}$ & $0.255[\mathrm{~W} / \mathrm{mK}]$ & $(30)$ \\
\hline$\lambda_{\mathrm{c}, \text { radial }}$ & $0.071[\mathrm{~W} / \mathrm{mK}]$ & $(30)$ \\
\hline$\lambda_{\mathrm{c}, \text { axial }}$ & $0.105[\mathrm{~W} / \mathrm{mK}]$ & $(30)$ \\
\hline$\lambda_{\mathrm{v}}$ & $0.0258[\mathrm{~W} / \mathrm{mK}]$ & $(30)$ \\
\hline$\varepsilon_{\mathrm{w}, 0}$ & 0.4 & $(30)$ \\
\hline$M_{\mathrm{g}}$ & $0.038[\mathrm{~kg} / \mathrm{mol}]$ & $(30)$ \\
\hline$M_{\mathrm{t} 1}$ & $0.162[\mathrm{~kg} / \mathrm{mol}]$ (assumed to be levoglucosan) & \\
\hline$M_{\mathrm{t} 2}$ & $0.11[\mathrm{~kg} / \mathrm{mol}]$ & $(30)$ \\
\hline
\end{tabular}

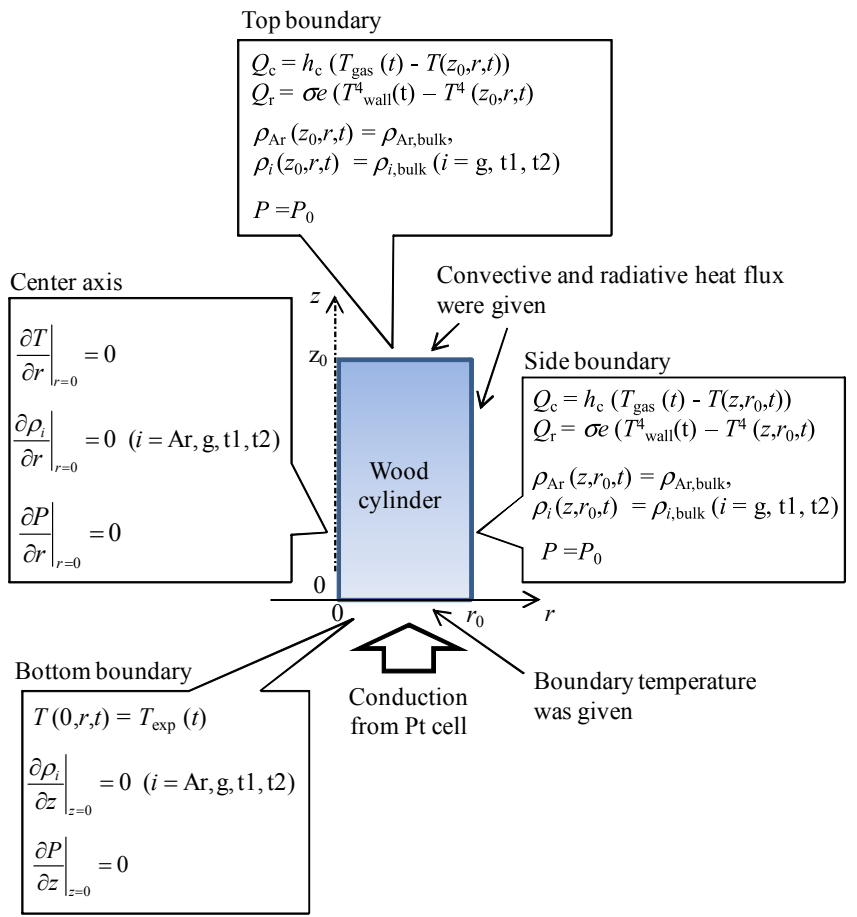

Figure 4 Schematic diagram of computational domain and boundary condition

Calculation algorithm is as follows:

1. Grid generation

2. Initial condition set

3. Time update

4. Calculate reaction kinetics parameters using Table 3 
5. Calculate physical properties of solid sample

6. Solve the solid mass conservation equations (eqs. (1) - (3))

7. Solve the mass conservation equations for eqs. (4)-(7), energy conservation equation for eq. (16) and total pressure equations for eq. (22) with iterative procedure and calculate the velocity using eqs. $(11,12)$ until calculation is converged.

8. Return to step 3 if intra-particle temperature distribution is not uniform (maximum temerature difference between current and previous one is larger than $0.005 \mathrm{~K}$

$\left.\left(\max \left|T-T_{\text {old }}\right|>0.005[\mathrm{~K}]\right)\right)$.

9. End.

To investigate the effect of intra-particle heat transfer on pyrolysis characteristics, calculation with uniform temperature was also carried out. In uniform temperature calculation, intra-particle temperature was assumed to be uniform and the thermometric temperature whose position is shown in Figure 1 was given as intra-particle temperature, instead of solving energy conservation equation (eq. 16). Energy conservation equation was solved in all calculation results except for Figs. 6-8 with a caption of uniform temperature.

\section{Results and discussion}

\subsection{Dynamics of wood cylinder pyrolysis}

Figure 5 shows instantaneous contours of wood cylinder at different heating rate when the solid weight fraction is about 0.3. Figure 5(a) shows temperature contour. With increasing heating rate, temperature gradient appears. Figure 5(b) shows primary tar formation rate. Primary tar formation reaction is progressed from cylinder surface to inner solid in all heating rate, and biomass is converted to char from outside. In this figure, the primary tar formation occurs in the solid at $30 \mathrm{~K} / \mathrm{s}$, although tar formation is widely progressed at 5 and $10 \mathrm{~K} / \mathrm{s}$. This is because pyrolysis is almost terminated at the surface at $30 \mathrm{~K} / \mathrm{s}$ due to the rapid increase of temperature. Figure 5 (c) shows velocity vectors of volatile products. First, volatile products are formed in the sample, and it causes intra-particle pressure generation which is the driving force of velocity. Then, volatile products move towards the surface where pressure is low. Rapid formation of volatile products caused high pressure generation. This is the reason why velocity increases with increasing heating rate as shown in Figure 5 (c). And, outside velocity is higher than inner velocity since the char permeability is much higher than that of raw wood as shown in Table 4. Pressure difference is also important factor, however, the change of pressure difference between inside and outside is not so large compared with permeability. Figure 5 (d) shows primary tar decomposition rate. The primary tar decomposition rate is the highest at $30 \mathrm{~K} / \mathrm{s}$. This is because primary tar formed in the sample passes through the char layer with high temperature enough to progress tar decomposition at high heating rate. It indicates the intra-particle tar decomposition rate increases with increasing heating rate, although the intra-particle residence time decreases. Intra-particle tar decomposition is discussed later.

\subsection{Temperature profile and weight fraction history}

Figures 6-8 show the pyrolysis characteristics of the sample at $5,10,30 \mathrm{~K} / \mathrm{s}$, respectively. The profiles characteristics of the measured temperatures are well reproduced by the calculation in all heating rate. However, measured temperature histories before pyrolysis are a little lower than the calculations at $5 \mathrm{~K} / \mathrm{s}$ and $10 \mathrm{~K} / \mathrm{s}$. With progression of pyrolysis, the effect of thermal conductivity of wood on temperature distribution becomes small, and other effects such as reactions play an important role. Therefore, the reason why calculated temperature is a little higher than experimental one before pyrolysis is approximation of thermal conductivity of raw wood. Thermal conductivity also varies with location within the sample and between different samples. Many researchers approximated this anisotropic 


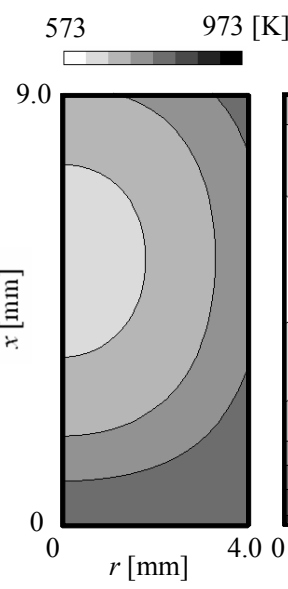

(1) $r_{\mathrm{h}}=5 \mathrm{~K} / \mathrm{s}$, $t=75 \mathrm{~s}$

(a) Temperature contour

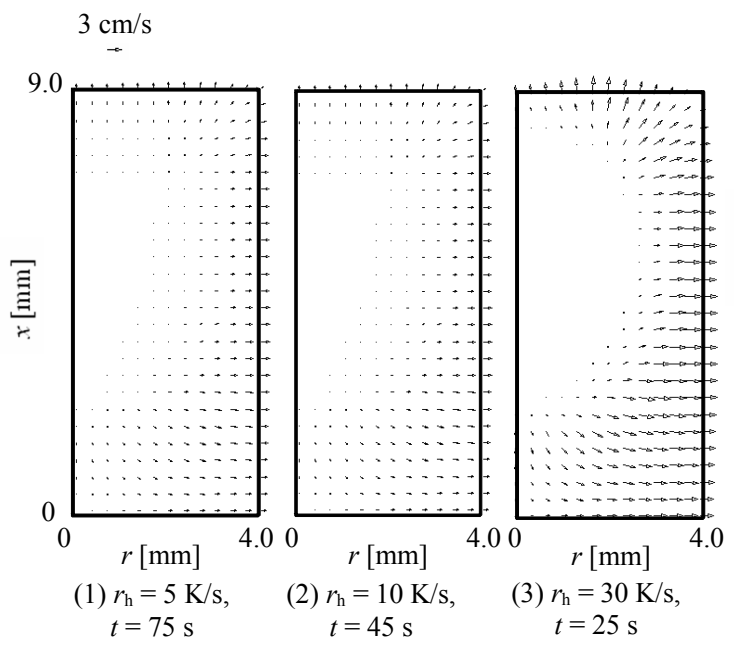

(c) Velocity vectors

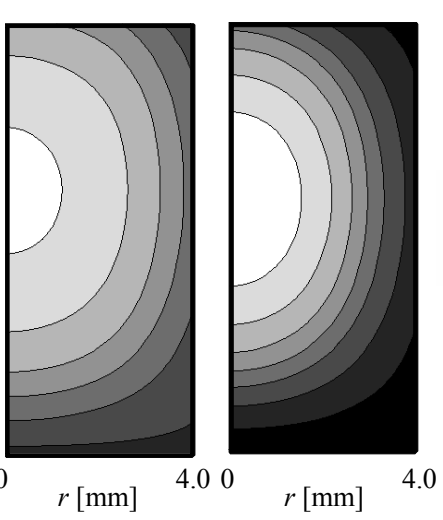

(3) $r_{\mathrm{h}}=30 \mathrm{~K} / \mathrm{s}$, $t=25 \mathrm{~s}$

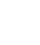

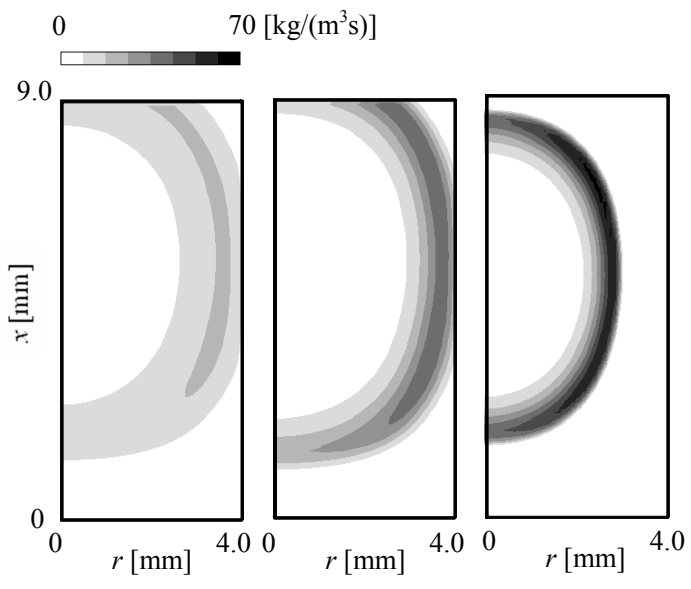

(1) $r_{\mathrm{h}}=5 \mathrm{~K} / \mathrm{s}$, $t=75 \mathrm{~s}$

(2) $r_{\mathrm{h}}=10 \mathrm{~K} / \mathrm{s}$, $t=45 \mathrm{~s}$

(3) $r_{\mathrm{h}}=30 \mathrm{~K} / \mathrm{s}$, $t=25 \mathrm{~s}$

(b) Primary tar formation rate

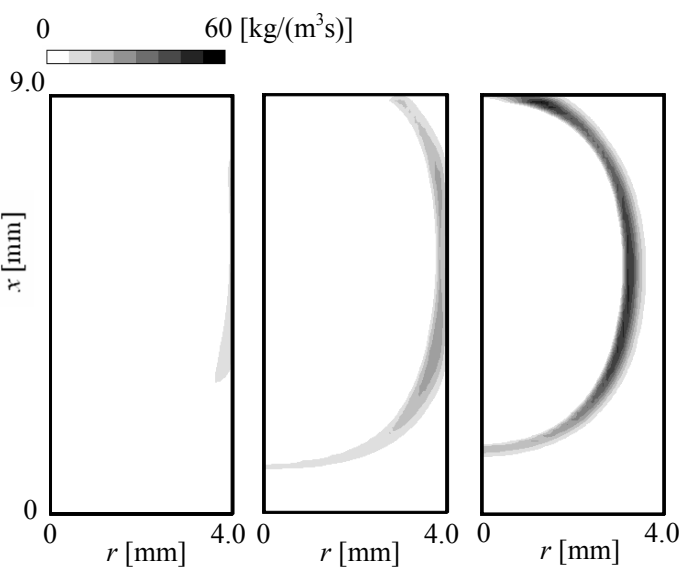
(1) $r_{\mathrm{h}}=5 \mathrm{~K} / \mathrm{s}$, $t=75 \mathrm{~s}$
(2) $r_{\mathrm{h}}=10 \mathrm{~K} / \mathrm{s}$, $t=45 \mathrm{~s}$
(3) $r_{\mathrm{h}}=30 \mathrm{~K} / \mathrm{s}$, $t=25 \mathrm{~s}$

(d) Primary tar decomposition rate

Figure 5 Instantaneous contour of wood cylinder at the solid weight fraction of about 0.3 and inhomogeneous behavior to perform calculation ${ }^{(29)}$. While this is approximate, the error is expected to be small ${ }^{(29)}$. At $30 \mathrm{~K} / \mathrm{s}$, pyrolysis reaction starts relatively quickly due to its high heating rate. Thus, the effect of thermal conduction of raw wood is relatively small, and the such kind of error is not found at $30 \mathrm{~K} / \mathrm{s}$.

When heating rate is 5 or $10 \mathrm{~K} / \mathrm{s}$, first, temperature increases gradually, then decreasing slope of temperature can be seen in both experiment and calculation around $60 \mathrm{sec}$ for $5 \mathrm{Ks}$ and $40 \mathrm{sec}$ for $10 \mathrm{~K} / \mathrm{s}$. A explanation would be that this decreasing of slope is caused by the endothermic heat of pyrolysis, as pointed by many researchers ${ }^{(29,36)}$. Next, sudden temperature change appears around $70 \mathrm{sec}$ for $5 \mathrm{~K} / \mathrm{s}$ and $50 \mathrm{sec}$ for $10 \mathrm{~K} / \mathrm{s}$, although heating rate of thermometric point is kept at constant. It is difficult to explain an significant increase in the slope of the temperature by only exothermic reactions. An increase in the slope can be explained by the change in the heat capacity. While sample weight decreases, an amount of gas is formed. Heat capacity of gas formed during pyrolysis is quite less than that of char. The overall heat capacity just temperature increases suddenly. As for $30 \mathrm{~K} / \mathrm{s}$, shrinking and swelling of wood cylinder is found after pyrolysis. And, sample split is also observed. This swelling behavior can be expressed by internal pressure. Pressure build up is the result of large volatiles flow in thick char and thin partially pyrolyzed wood ${ }^{(10)}$. This effect is not considered in the calculation, and char cracking is expected to enhance heat transfer between gas and solid. Therefore, as shown in Figure 8(a), calculation is slightly lower than 
experiment around $20 \mathrm{sec}$, at which pyrolysis reaction is progressed, because cracking and swelling are not considered in this calculation.

As shown in weight fraction history, when intra-particle heat transfer is considered, numerical result is in good agreement with measurement. Contrarily, predicted weight fraction history without intra-particle heat transfer consideration grossly under estimates experimental data. With increasing heating rate, the difference between experiment and calculation without considering intra-particle heat transfer increases. This is because temperature gradient, especially for radial direction, increases with an increase in heating rate. Thermal conductivity for radial direction is lower than that for axial direction. Intra-particle heat transfer plays an important role in pyrolysis of wood cylinder.

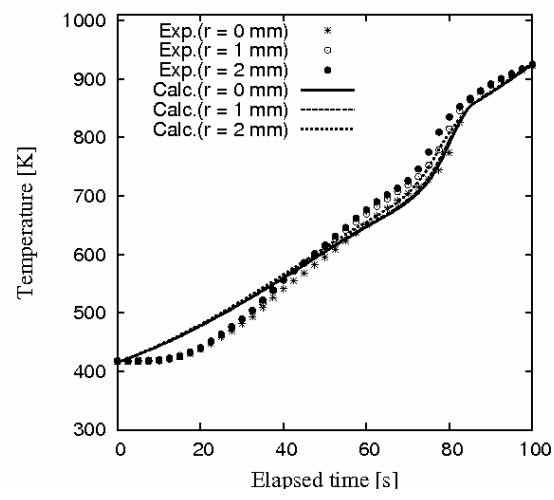

(a) temperature history

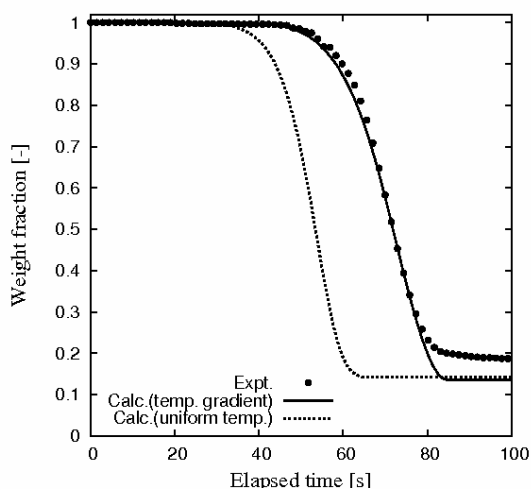

(b) weight fraction history

Figure 6 Pyrolysis characteristics at $5 \mathrm{~K} / \mathrm{s}$

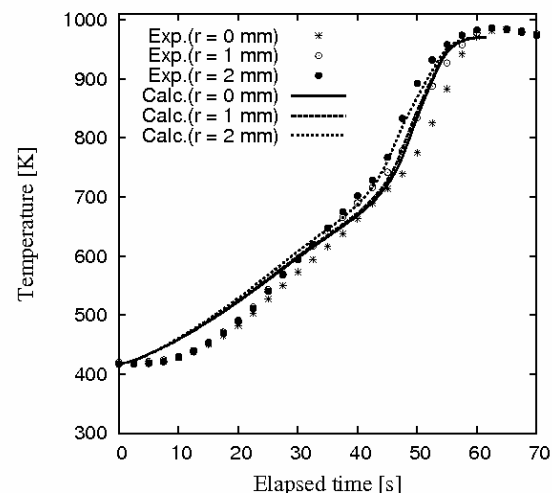

(a) temperature history

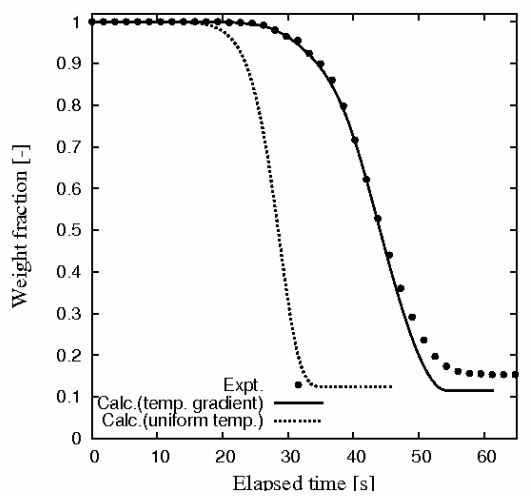

(b) weight fraction history

Figure7 Pyrolysis characteristics at $10 \mathrm{~K} / \mathrm{s}$

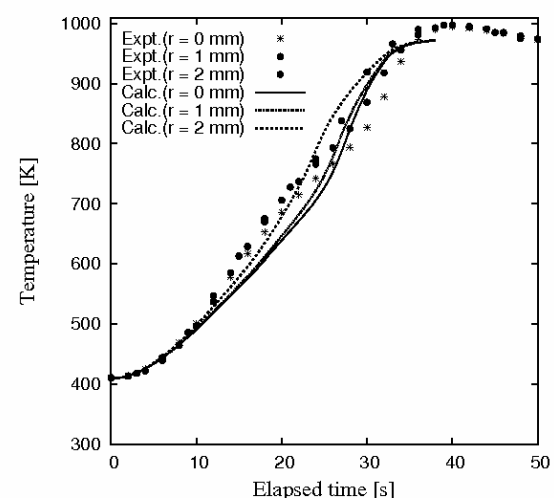

(a) temperature profile

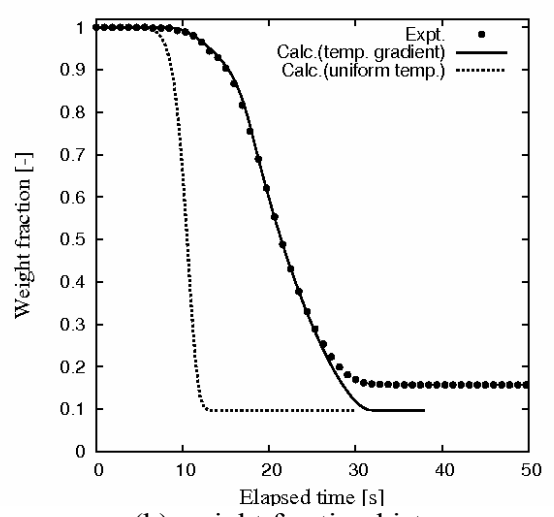

(b) weight fraction history

Figure 8 Pyrolysis characteristics at $30 \mathrm{~K} / \mathrm{s}$ 
Even when intra-particle heat transfer is considered, calculated char yields are little lower than experimental ones. It is very difficult to show the reason because many complex phenomena are included to calculate char formartion. One of the reasons may be the limitation of global reaction mechanisms. Combination with detailed pyrolysis model such as CPD (Chemical Percoration Devolatilization) ${ }^{(37)}$ model will be future works.

\subsection{Primary tar secondary reactions}

Figure 9 shows the calculated and measured total tar yields at different heating rates. Total tar weight, $W_{\text {tar }}$, was estimated numerically by:

$$
W_{\mathrm{tar}}=\int_{0}^{t} \int_{A}\left(\rho_{\mathrm{t} 1}+\rho_{\mathrm{t} 2}\right) V d A d t
$$

where $V$ is vertical gas velocity against solid surface, $A$ is solid surface area, and $t$ is elapsed time during heating. Tar yield is $W_{\text {tar }}$ normalized by initial solid weight.

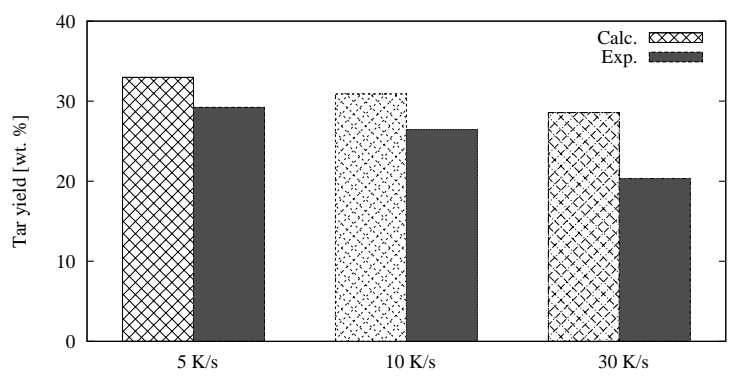

Figure 9 Calculated and measured total tar yields at different heating rates

As shown in Figure 9, both experimental and numerical results showed that total tar yield decreased with increasing heating rate, although previous research has reported that tar yield of cypress sawdust increases with increasing heating rate ${ }^{(36)}$. In fact, opposite results are obtained when wood cylinder is used. This is because intra-particle tar decomposition is enhanced within the wood cylinder before tar is eventually released as discussed later. Simulation results overestimate experimental results for total tar yield. This is due to the fact that heterogeneous reaction is not considered for intra-particle tar decomposition in this study. Intra-particle tar decompostion may occur homogeneously in the pores of the sample while undergoing primary degradation and heterogeneously over the char surfaces and extra-particle surfaces ${ }^{(27)}$. However, due to lack of kinetic data for heterogeneous reactions, only homogeneous reactions are considered in this study. There is a possibility to optimize the experimental conditions during primary pyrolysis to significantly facilitate intra-particle tar decompostion reactions, thereby drastically reducing the overall tar yield.

Figure 10 shows the variation of the ratio of amount of intra particle tar decomposition rate $\left(R_{\mathrm{s}}\right)$ to the amount of primary tar formation reaction rate $\left(R_{\mathrm{p}}\right)$. The ratio of $R_{\mathrm{s}}$ to $R_{\mathrm{p}}$ is simulated at each heating rate. An amount of primary tar formation reaction rate $\left(R_{\mathrm{p}}\right)$, and that of intra-particle tar decomposition rate $\left(R_{\mathrm{s}}\right)$, are estimated as:

$$
\begin{aligned}
& R_{\mathrm{p}}=\int_{0}^{V_{\mathrm{c}}} \int_{0}^{t} k_{\mathrm{t} 1} \rho_{\mathrm{s}} d t d V_{\mathrm{c}} \\
& R_{\mathrm{s}}=\varepsilon \int_{0}^{V_{\mathrm{c}}} \int_{0}^{t}\left(a k_{\mathrm{g} 2}+b k_{\mathrm{g} 2}+k_{\mathrm{c} 2}\right) \rho_{\mathrm{t} 1} d t d V_{\mathrm{c}}
\end{aligned}
$$

where $d V_{\mathrm{c}}$ is the each cell volume (control volume) and $t$ is elapsed time during heating.

As shown in the Figure 10, an increase in this ratio with increasing heating rate implies that though primary tar formation reaction and secondary tar decomposition reactions are enhanced by increase in heating rate, but the latter becomes dominant with increasing heating rate. Therefore, tar is decomposed before it is released from cylinder surface. It is 
clearly shown intra-particle tar decomposition affects tar yield strongly. Detailed reaction mechanisms of intra-particle tar decomposition will be the subject of further study.

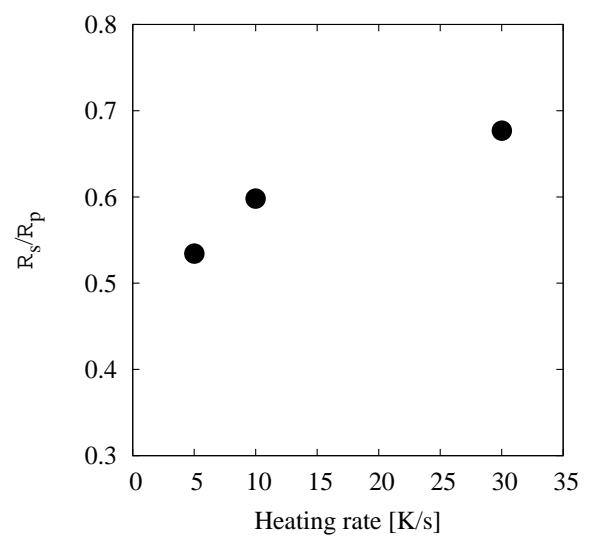

Figure 10 Ratio of amount of intra-particle tar decomposition reaction rate to that of tar formation reaction rate

\section{Conclusion}

Pyrolysis characteristics of cylindrical woody biomass were investigated both numerically and experimentally with emphasis on intra-particle heat transfer and tar decompostion. And, the possibility of tar yield reduction through intra-particle tar decomposition during the pyrolysis process of cylindrical woody biomass was discussed. A two-dimensional, time-dependent single particle model was developed and used to simulate the pyrolysis process at three different heating rates. The simulated pyrolysis characteristics with considering intra-particle heat transfer were in good agreement with the measured data. However, predicted weight fraction histories without intra-particle heat transfer consideration differed from experimental measurements with the degree of difference increasing with increase in heating rate. It indicated that intra-particle heat transfer played an important role in pyrolysis process of wood cylinder whose size was close to that used in actual biomass combustor. Moreover, both experimental and numerical results showed total tar yield decreased with increasing heating rate. This was because both primary tar formation reaction and intra-particle tar decomposition reactions were enhanced by increase in heating rate but the latter became dominant with increase in heating rate. It is clearly shown intra-particle tar decomposition strongly affects tar yield.

\section{Acknowledgement}

This research was partially supported by JFE 21 st Century Foundation.

\section{Nomenclature}

$A$ : pre-exponential factor

$a$ : stoichiometric coefficient

$B$ : permeability

$\left[\mathrm{m}^{2}\right]$

$b$ : stoichiometric coefficient

$C_{\mathrm{p}}$ : specific heat

$d_{\text {pore }}$ : pore diameter

$[\mathrm{J} /(\mathrm{kg} \mathrm{K})]$

$E$ : activation energy

$[\mathrm{m}]$

$e$ : emissivity

$[\mathrm{J} / \mathrm{mol}]$

$[-]$ 
$g$ : gravity

$h_{c}$ : convective heat transfer coefficient

$k$ : reaction rate constant

$M$ : molecular weight

$P$ : pressure

$Q$ : heat generation

$Q_{c}$ : convective heat flux

$Q_{r}$ : radiative heat flux

$R$ : universal gas constant

$x, r$ : cylindrical coordinate

$x_{0}$ : axis at surface

$r_{0}$ : radius at surface

$r_{\mathrm{h}}$ : heating rate

$S$ : source term

$T$ : temperature

$T_{\text {env }}(t)$ : temperature of environment

$t$ : time

$U$ : axial velocity component

$V$ : radial velocity component

$V_{\mathrm{c}}$ : volume

$\varepsilon$ : porosity

$\varepsilon_{0}$ : initial porosity

$\Delta h$ : heat of pyrolysis

$\lambda$ : thermal conductivity

$\mu$ : viscosity

$\rho_{\text {Ar, t, g: }}$ mass concentration of each species

$\rho_{\mathrm{s}, \text { is, c }}$ : density of each solid

$\rho_{\mathrm{w}, 0}:$ initial density of wood

$\sigma$ : Stafan-Boltzmann constant

$\eta$ : degree of pyrolysis

\section{Subscripts}

Ar: Argon

c: char

c2: secondary char

cond: conductive

g: gas

g2: secondary gas

is: intermediate solid

$r$ : radial direction

rad: radiative

s: solid

t1: primary tar

t2: secondary tar

v: total volatiles

w: wood

$\mathrm{z}$ : axial direction

0 : surface $\left[\mathrm{m} / \mathrm{s}^{2}\right]$

$\left[\mathrm{W} /\left(\mathrm{m}^{2} \mathrm{~K}\right)\right]$

$[1 / \mathrm{s}]$

$[\mathrm{kg} / \mathrm{mol}]$

[Pa]

$\left[\mathrm{W} / \mathrm{m}^{3}\right]$

$\left[\mathrm{W} / \mathrm{m}^{2}\right]$

$\left[\mathrm{W} / \mathrm{m}^{2}\right]$

$[\mathrm{J} /(\mathrm{mol} \mathrm{K})]$

[m]

[m]

[m]

$[\mathrm{K} / \mathrm{s}]$

[K]

[K]

[s]

$[\mathrm{m} / \mathrm{s}]$

$[\mathrm{m} / \mathrm{s}]$

$\left[\mathrm{m}^{3}\right]$

[-]

[-]

$[\mathrm{kJ} / \mathrm{kg}]$

[W/(m K)]

$[\mathrm{kg} /(\mathrm{m} \mathrm{s})]$

$\left[\mathrm{kg} / \mathrm{m}^{3}\right]$

$[\mathrm{kg} / \mathrm{m} 3]$

$\left[\mathrm{kg} / \mathrm{m}^{3}\right]$

$\left[\mathrm{W} /\left(\mathrm{m}^{2} \mathrm{~K}^{4}\right)\right]$ 


\section{Reference}

(1) Parveen M. et al., "Thermal decomposition behavior study of two agricultural solid wastes for production of bio-fuels by pyrolysis technology, Journal of Thermal Science and Technology, 6 (2011), 132-139.

(2) Ito Y. et al., "Ignition behavior of bio-coke (highly densified biomass fuel) in high-temperature air flows, 6 (2011), 111-122..

(3) Li, X.T. et al., "Biomass gasification in a circulating fluidized bed", Bio Bioenerg., 26 (2004), 171-193.

(4) M. Stahl et al., Industrial processes for biomass drying and their effects on the quality properties of wood pellets, Biomass Bioenergy 27 (2004), 621-628.

(5) Babu B.V. and Chaurasia A.S., "Modeling for pyrolysis of solid particle: kinetics and heat transfer effects", Energ. Conv. Management, 44 (2003), 2251-2275.

(6) Sadhukhan A.K., "Modeling and experimental study studies on pyrolysis of biomass particles”, J. Anal Appl Pyro., 81 (2008), 183-192.

(7) Jalan R.K. and Srivastava V.K., "Studies on pyrolysis of a single biomass cylindrical pellet: kinetic and heat transfer effects", Energ Conv. Management , 40 (1999), 467-494.

(8) Devi L. et al., "A review of the primary measures for tar elimination in biomass gasification processes", Bio Bioenerg., 24 (2003), 125-140.

(9) Han J. and Kim H., "The reduction and control technology of tar during biomass gasification /pyrolysis: an overview", Renew. Sust Energ Rev., 12 (2008), 397-416.

(10) Di Blasi C. et al., "Product distribution from pyrolysis of wood and agricultural residues" Ind. Eng. Chem. Res., 38 (1999), 2216-2224.

(11) Gronli M.G. and Melaaen M.C., "Mathematical model for wood pyrolysis- comparison of experimental measurements with model predictions" Energ. Fuel, 14 (2000), 791-800.

(12) Williams P.T. and Besler S., "The influence of temperature and heating rate on the slow pyrolysis of biomass", Renew Energ., 7-3 (1996), 233-250.

(13) Chan W.R. et al., "Modelling and experimental verification of physical and chemical processes during pyrolysis of a large biomass particle" Fuel, 64 (1985), 1505-1513.

(14) Babu B.V. and Chaurasia A.S., "Heat transfer and kinetics in the pyrolysis of shrinking biomass particle”, Chem Eng Sci, 59 (2004), 1999-2012.

(15) Nunn T.R. et al., "Product compositions and kinetics in the rapid pyrolysis of sweet gum hardwood”, Ind. Eng. Chem., Process Design Dev., 24-3 (1985), 836-844.

(16) Varhegyi G. et al., "Kinetics of the thermal decomposition of cellulose, hemicellulose and sugarcane bagasse", Energ. Fuel, 3-3 (1989), 329-335.

(17) Liliedahl T. and Sjostrom K., "Heat transfer controlled pyrolysis kinetics of a biomass slab, rod or sphere", Bio Bioenerg., 15-6 (1998), 503-509.

(18) Antal M.J.J. et al., "Cellulose pyrolysis kinetics: revisited”, Ind. Eng. Chem. Res., 37-4 (1998), 1267- 1275.

(19) Guo J. and La C., "Kinetic study of pyrolysis of extracted oil palm fiber: isothermal and nonisothermal conditions", J. Therm Anal Calorimetry, 59 (2000), 763-774

(20) Suuberg M.E. et al., "Two-regime global kinetics of cellulose pyrolysis: the role of tar evaporation" Twenty-sixth Symp (International) on combustion (1996), 1515-21.

(21) Piskorz J. et al., "On the mechanism of the rapid pyrolysis of cellulose", J Anal Appl Pyrolysis, 9 (1986), 121-137.

(22) Graham R.G. et al., "The kinetics of vapor-phase cellulose fast pyrolysis reactions", Bio Bioenerg, 7-(1-6) (1994), 33-47.

(23) Wagenaar B.M. et al., "Pyrolysis of biomass in the rotating cone reactor modeling and experimental justification” Chem. Eng. Sci., 49-24, B (1994), 5109 - 5126.

(24) Janse A.M.C. et al., "Modelling of flash pyrolysis of a single wood particle", Chem. 
Eng. Processing, 39 (2000), 239-252.

(25) Di Blasi C. and Branca C., "Kinetics of primary product formation from wood pyrolysis", Ind Eng Chem Res, 40 (2001), 5547-5556.

(26) Shen D.K. et al. "Modeling pyrolysis of wet wood under external heat flux", Fire Safety, 42 (2007), 210-217.

(27) Di Blasi C. "Modeling chemical and physical processes of wood and biomass pyrolysis", Prog Energ Combust Sc., 34 (2008), 47-90.

(28) Prakash N., Karunanithi T. "Advances in modeling and simulation of biomass pyrolysis”, Asian J. Scientific Res., 2-1 (2009), 1-27.

(29) Park W.C. et al., "Experimental and theoretical investigation of heat and mass transfer processes during wood pyrolysis" Combust. Flame, 157 (2010), 481- 494.

(30) Glaidster S.D. The prediction of chemical kinetics, heat and mass transfer processes during one and two-dimensional pyrolysis of a large wood pellet. PhD. Thesis, University of Washington1987, in: Ratte J. et al. "Mathematical modeling of slow pyrolysis of a particle of treated wood" J. Haz. Mater., 17 (2009), 1023-1040.

(31) Morf P. et al., "Mechanisms and kinetics of homogeneous secondary reactions of tar from continuous pyrolysis of wood chips", Fuel, 81 (2002), 843-853.

(32) Di Blasi C. "Heat, momentum, and mass transport through a shrinking biomass particle exposed to thermal radiation. Chem. Eng. Sci., 51-7 (1996), 1121-1132.

(33) Mok W.S.L. and Antal M.J. Jr. "Effects of pressure on biomass pyrolysis. II. Heat of reaction of cellulose pyrolysis", Thermochimica Acta, 68 (1983), 165-186.

(34) Jarvinen M. P., Zevenhoven R. and Vakkilainen E. K. "Auto-gasification of a biofuel", Combustion and Flame, 131 (2002) 357-370.

(35) Pyle D.L. and Zoror C.A. "Heat Transfer and kinetics in the low temperature pyrolysis of solids", Chemical Engineering Science, 39 (1984), 147-158.

(36) Morten G.C. and Morten C.M., "Mathematical model for wood pyrolysis-comparison of experimental measurements with model predictions", Energy \& Fuels, 14 (2000), 791-800.

(37) Okada T., Okumura Y. and Okazaki K., "Prediction of pyrolysis process for wood and grass biomass by CPD model", Journal of the Japan Institute of Energy, 87 (2008), 852-861. 